nonuclear cells. Immunohistochemical stains can help establish the diagnosis as the mononuclear cells usually stain with antibodies against S-100 protein and OKT-6 [1-3, 9]. As the disease progresses, histiocytes accumulate hemosiderin, iron, and lipid to become xanthomatous cells, and eventually fibrous reaction can be seen $[2,4,5]$.

Most solitary lesions, as in this case, heal after treatment with excisional biopsy, curettage, and occasionally bone grafting. Refractory cases have responded to radiation treatment, and recently local injection of methylprednisone has been used in treatment $[1,4,6]$.

The radiographic appearance of eosinophilic granuloma can be extremely variable. The differential diagnosis may include fibrous dysplasia, neoplasia (Ewing's sarcoma, lymphoma, leukemia, metastatic neuroblastoma, hemangioma), inflammation (osteomyelitis, Brodie's abscess), hyperparathyroidism with brown tumors, or Gaucher's disease $[2,5,6]$. The features in this case were most compatible with a diagnosis of eosinophilic granuloma, given the age of the patient, the location, and the radiographic demonstration of a lucent diaphyseal lesion with marked periosteal reaction.

\section{References}

1. Mayo-Smith W, et al. Case Report 542 Skeletal Radiol 1989; 18: 245-247.

2. Resnick D, Niwayama G. Diagnosis of bone and joint disorders. 2nd ed. Philadelphia: Saunders, 1988: 2429-2439.
3. David R, Oria R, Kumar R, et al. Radiologic features of eosinophilic granuloma of bone. AJR 1989; 153: 1021-1026.

4. McCullough CJ. Eosinophilic granuloma of bone. Acta Orthop Scand 1980; 51: 389-398

5. Bergholz M, Schaver A, Poppe H. Diagnostic and differential diagnostic aspects in histiocytosis $\mathrm{X}$ diseases. Pathol Res Pract 1979; 166: 59-71.

6. Greis P, Hankin F. Eosinophilic granuloma: the management of solitary lesions of bone. Clin Orthop Rel Res 1990; 257: 204-211.

7. Mitnick J, Pinto R. Computed tomography in the diagnosis of eosinophilic granuloma. J Comput Assist Tomogr 1980; 4: 791-793.

8. Skully R, et al. Case records of the Massachussetts General Hospital, case 281986. N Engl J Med 1986; 315: 179-185.

9. Huvos AG. Bone tumors, diagnosis, treatment and prognosis. 2nd ed. Philadelphia: Saunders, 1991: 695-707.

\title{
Quiz: Case report 854
}

There are five winners:

Narendrakumar Patel, M.D., Newburgh, New York, USA

Alan Oestreich, M.D., Cincinnati,Ohio, USA

Jose Burgos Flor, Buenos Aires, Argentina

Virinder Mohan, M.D., Muscat, Sultanate of Oman

George J. Zafiroski, M.D., Skopje, Republic of Macedonia 